\title{
Correlation between Depth of Myometrial Invasion and Degree of Lymph Node Affection in Cases of Endometrial Cancer
}

\author{
Ahmed Essmat \\ Department of Obstetrics and Gynecology, El-Shatby Maternity University Hospital, Alexandria, Egypt \\ Email: princeessmat@gmail.com
}

How to cite this paper: Essmat, A. (2021) Correlation between Depth of Myometrial Invasion and Degree of Lymph Node Affection in Cases of Endometrial Cancer. Open Journal of Obstetrics and Gynecology, 11, 360-368.

https://doi.org/10.4236/ojog.2021.114036

Received: March 9, 2021

Accepted: April 17, 2021

Published: April 20, 2021

Copyright $\odot 2021$ by author(s) and Scientific Research Publishing Inc. This work is licensed under the Creative Commons Attribution International License (CC BY 4.0).

http://creativecommons.org/licenses/by/4.0/

\begin{abstract}
Introduction: Endometrial cancer is the fourth most frequent cancer in females. Many factors can affect prognosis of this type of cancer, these mainly are the degree of myometrial invasion by the tumour, pelvic and paraaortic lymph node spread as well as the tumour histological type (endometrioid vs non-endometrioid type). transvaginal ultrasound (TVS) is a highly accurate and easy method for preoperative evaluation of myometrial invasion. Aim of the Work: The aim of this work is to assess if there is relation between the depth of myometrial invasion by the tumor and the rate of lymph node involvement in cases of endometrial cancer. Results: It was found that there was a significant relation between lymph node affection and the depth of myometrial invasion, all the positive lymph node affections cases had myomterial invasion $>50.0 \%$. Conclusion: The incidence of pelvic lymph node affection is very high in cases where the myometrium is deeply infiltrated with the tumor. Assessment of myometrial invasion preoperatively by TVU and microscopically by pathological examination of the myometrium after hysterectomy provides an accurate estimation of the rate of pelvic lymph node affection and hence necessitates lymphadenectomy procedures in cases where myometrium is deeply infiltrated by the tumor and omitted in cases where it is tumor free.
\end{abstract}

\section{Keywords}

Endometrial Cancer, Endometrial Carcinoma, Lymph Node Affection, Myometrial Invasion

\section{Introduction}

Endometrial cancer is the fourth most frequent cancer in females. It is also the 
most curable of the 10 most common cancers in women and it is the most frequent and curable of the gynecologic malignancy [1]. Many factors can affect prognosis of this type of cancer, these mainly are the degree of myometrial invasion by the tumour, pelvic and para-aortic lymph node spread as well as the tumour histological type (endometrioid vs non-endometrioid type) [2]. The degree of myometrial invasion was classified as none, $<50 \%$ (superficial) and $>50 \%$ (deep). Many diagnostic modalities are used to assess the degree of myometrial invasion preoperatively such as transvaginal ultrasound (TVU), CT scan and MRI with variable degrees of accuracy. TVU is a highly accurate and easy method for preoperative evaluation of myometrial invasion. Contrast-enhanced MR imaging is significantly superior to TVU and unenhanced T2-weighted MR imaging for detecting the depth of myometrial invasion. Although higher sensitivity has been reported for CT scan than MRI for detection of retroperitoneal lymph nodes involvement, previous meta-analysis showed that diagnostic performance of dynamic contrast-enhanced MRI for myometrial invasion detection is higher than CT or TVU [3]. The staging accuracy by means of MRI in patients with endometrial cancer has been reported between $83 \%$ to $92 \%$ [4].

\section{Subjects and Methods}

50 women, median age 55 (range 50 - 60), attending the Gyne-oncology Clinic at El-Shatby Maternity Hospital, Alexandria University Hospital over a 12-month period, were enrolled in the study after taking a written concent and approval of ethics committee.

\section{Inclusion criteria:}

1) Cases with proved endometrial carcinoma on histopathological examination after biopsy of the endometrium.

2) Both type 1 and type 2 endometrial cancers.

3) Postmenopausal patients having endometrial thickness more than $5 \mathrm{~mm}$ in TVU examination.

\section{Exclusion criteria:}

1) Cases with advanced endometrial cancer with positive peritoneal metastasis.

2) Patients with other cases of postmenopausal uterine bleeding other than endometrial cancer.

All women had experienced an episode or more of post-menopausal uterine bleeding (PMUB). A transvaginal ultrasound (TVU) was done to assess uterine size, endometrial thickness (ET) and endometrial, myometrial junctional zone (ENJ). A cutoff level of ET of more than $5 \mathrm{~mm}$ was included in the study. EMJ was also assessed for regularity or irregularity. An irregular EMJ was considered to be a possibility of myometrial invasion. Patients with irregular EMJ, bulky tumour size $(>20 \mathrm{~mm}$ ) or non endometrioid type were undergone MRI examination to further predict myometrial invasion and assess pelvic lymph node (LN) status. 
These ladies had undergone an office endometrial sampling or a conventional D\&C biopsy and were pathologically proved for endometrial carcinoma (endometrioid or non endometrioid types). All other causes of PMUB were excluded.

In all cases, laparotomy was done. Total abdominal hysterectomy with bilateral salpingooophorectomy (TAH w BSO) and bilateral pelvic lymphadenectomy was done. Uterus was incised and assessed for gross myometrial invasion by the naked eye. All sampled were send for histopathological analysis to assess the tumor pathological type, grade, depth of myometrial invasion, cervical involvement and PLN status. Finally, the clinical results were correlated to radiological and pathological ones.

\section{Results}

\subsection{Statistical Analysis}

The Data was collected and entered into the personal computer. Statistical analysis was done using Statistical Package for Social Sciences (SPSS/version 21) software.

The statistical test used as follow:

Arthematic mean, standard deviation, for normally distributed data, while for categorized data the number and percent was used to represent the data. Comparison between two categorized parameters Chai square test was used. The level of significant was 0.05 .

\subsection{Sample Size}

Sample size was calculated based on a previous study and by using Med Calc statistical software. Assuming area under ROC to be 0.80 , an alpha of 0.05 and power of study $90.0 \%$, a typical advice is to reject the null hypothesis $\mathrm{H} 0$ if the corresponding $\mathrm{p}$-value smaller than 0.05 , a minimum sample size required was 50 patients will be required for this study (Tables 1-3).

Table 4, shows the relation between myometrial invasion and positive lymph node affection, it was found that there was a significant relation between lymph node affection and and the depth of myometrial invasion, all the positive lymph node affections cases had myometrial invasion $>50.0 \%$.

Table 5, shows the relation between LV space and positive lymph node affection, it was found that there was a significant relation between LV space and lymph node affection, the majority (80.0\%) of positive cases lymph node affection was positive $\mathrm{LV}$ space.

Table 6, shows the relation between EMJ and positive lymph node affection, it was found that there was no significant relation between EMJ and lymph node affection ( $\mathrm{p}>0.05)$.

Table 7, shows the relation between EMJ and Myometrial invasion, it was found that there was no significant relation between EMJ and Myometrial inva$\operatorname{sion}(\mathrm{p}>0.05)$. 
Table 1. Basic demographic and clinical data of the studied patients group.

\begin{tabular}{|c|c|c|}
\hline & Number " $\mathrm{n}=50$ " & Percent \\
\hline \multicolumn{3}{|l|}{ Age } \\
\hline$<60$ & 17 & 34.0 \\
\hline$>60$ & 33 & 66.0 \\
\hline Median age (years) & \multicolumn{2}{|c|}{64.0} \\
\hline Mean \pm S.D. & \multicolumn{2}{|c|}{$63.28 \pm 8.01$} \\
\hline \multicolumn{3}{|l|}{ Endometrial thickness } \\
\hline$<20$ & 26 & 52.0 \\
\hline$>20$ & 24 & 48.0 \\
\hline Median thickness & \multicolumn{2}{|c|}{20.0} \\
\hline Mean \pm S.D. & \multicolumn{2}{|c|}{$20.54 \pm 9.90$} \\
\hline \multicolumn{3}{|l|}{ EMJ finding by TVU } \\
\hline IRREG & 36 & 72.0 \\
\hline REG & 14 & 28.0 \\
\hline \multicolumn{3}{|l|}{ CT finding } \\
\hline Free & 36 & 72.0 \\
\hline Positive findings & 14 & 28.0 \\
\hline \multicolumn{3}{|l|}{ MRI } \\
\hline Negative & 43 & 86.0 \\
\hline Positive findings & 7 & 14.0 \\
\hline \multicolumn{3}{|l|}{ Operation data } \\
\hline TAH with BSO & 17 & 34.0 \\
\hline TAH with $\mathrm{BSO}+\mathrm{LN}$ & 33 & 66.0 \\
\hline
\end{tabular}

Table 2. Distribution of the studied patients group regarding D\&C type and findings.

\begin{tabular}{ccc}
\hline & Number “ $\mathbf{n}=\mathbf{5 0}$ & Percent \\
\hline FC & 49 & \\
Endometrial sampling method & 1 & 98.0 \\
Hystroscopic guiding & & 2.0 \\
D\&C pathological findings & 10 & 20.0 \\
GI & 29 & 58.0 \\
GII & 7 & 14.0 \\
High grade & 2 & 4.0 \\
Mixed mullerian tumor & 2 & 4.0 \\
Clear cell carcinoma & & \\
\hline
\end{tabular}


Table 3. Distribution of the studied patients group regarding grade, LV space, myometrial invasion and lymph node affection.

\begin{tabular}{ccc}
\hline & Number “ $\mathbf{n}=\mathbf{5 0}$ & Percent \\
\hline Grade & 17 & 34.0 \\
I & 27 & 54.0 \\
II & 6 & 12.0 \\
High & & \\
LV space & 36 & 72.0 \\
Negative & 14 & 28.0 \\
Positive & & 6.0 \\
\hline Myometrial invasion & 3 & 42.0 \\
Negative & 21 & 52.0 \\
<50.0\% & 26 & \\
$>50.0 \%$ & & 90.0 \\
\hline Lymph node affection & 45 & 10.0 \\
Negative & 5 & \\
Positive & & \\
\hline
\end{tabular}

Table 4. Relation between myometrial invasion and positive lymph node affection.

\begin{tabular}{|c|c|c|c|c|c|}
\hline \multirow{3}{*}{$\begin{array}{l}\text { Myometrial } \\
\text { invasion }\end{array}$} & \multicolumn{4}{|c|}{ Lymph node affection } & \multirow{3}{*}{ Total } \\
\hline & \multicolumn{2}{|c|}{ Negative } & \multicolumn{2}{|c|}{ Positive lymph node affection } & \\
\hline & No. & $\%$ & No. & $\%$ & \\
\hline Negative & 3 & 6.7 & 0 & 0.0 & 3 \\
\hline$<50.0 \%$ & 21 & 46.7 & 0 & 0.0 & 21 \\
\hline$>50.0 \%$ & 21 & 46.7 & 5 & 100.0 & 26 \\
\hline Total & 45 & 100.0 & 5 & 100.0 & 50 \\
\hline $\mathrm{X}^{2}$ & \multicolumn{4}{|c|}{7.052} & \\
\hline $\mathrm{p}$ & \multicolumn{4}{|c|}{$0.029^{*}$} & \\
\hline
\end{tabular}

Table 5. Relation between LV space and positive lymph node affection.

\begin{tabular}{|c|c|c|c|c|c|}
\hline \multirow{3}{*}{ LV space } & \multicolumn{4}{|c|}{ Lymph node affection } & \multirow{3}{*}{ Total } \\
\hline & \multicolumn{2}{|c|}{ Negative } & \multicolumn{2}{|c|}{ Positive lymph node affection } & \\
\hline & No. & $\%$ & No. & $\%$ & \\
\hline Negative & 35 & 77.8 & 1 & 20.0 & 36 \\
\hline Positive & 10 & 22.2 & 4 & 80.0 & 14 \\
\hline Total & 45 & 100.0 & 5 & 100.0 & 50 \\
\hline $\mathrm{X}^{2}$ & \multicolumn{4}{|c|}{7.451} & \\
\hline $\mathrm{p}$ & \multicolumn{4}{|c|}{$0.018^{*}$} & \\
\hline
\end{tabular}


Table 6. Relation between EMJ and positive lymph node affection.

\begin{tabular}{|c|c|c|c|c|c|}
\hline \multirow{3}{*}{ EMJ } & \multicolumn{4}{|c|}{ lymph node affection } & \multirow{3}{*}{ Tota } \\
\hline & \multicolumn{2}{|c|}{ Negative } & \multicolumn{2}{|c|}{ Positive lymph node affection } & \\
\hline & No. & $\%$ & No. & $\%$ & \\
\hline Irregular & 32 & 71.1 & 4 & 80.0 & 36 \\
\hline Regular & 13 & 28.9 & 1 & 20.0 & 14 \\
\hline Total & 45 & 100.0 & 5 & 100.0 & 50 \\
\hline $\mathrm{X}^{2}$ & \multicolumn{4}{|c|}{0.176} & \\
\hline $\mathrm{p}$ & \multicolumn{4}{|c|}{0.657} & \\
\hline
\end{tabular}

Table 7. Relation between EMJ and positive lymph node affection.

\begin{tabular}{|c|c|c|c|c|c|}
\hline \multirow{3}{*}{$\begin{array}{l}\text { Myometrial } \\
\text { invasion }\end{array}$} & \multicolumn{4}{|c|}{ EMJ } & \multirow{3}{*}{ Tota } \\
\hline & \multicolumn{2}{|c|}{ Irregular } & \multicolumn{2}{|c|}{ Regular } & \\
\hline & No. & $\%$ & No. & $\%$ & \\
\hline Negative & 1 & 2.8 & 2 & 14.3 & 3 \\
\hline$>50.0 \%$ & 20 & 55.6 & 6 & 42.9 & 26 \\
\hline$<50.0 \%$ & 15 & 41.7 & 6 & 42.9 & 21 \\
\hline Total & 36 & 100.0 & 14 & 100.0 & 50 \\
\hline $\mathrm{X}^{2}$ & \multicolumn{4}{|c|}{2.54} & \\
\hline $\mathrm{p}$ & \multicolumn{4}{|c|}{0.281} & \\
\hline
\end{tabular}

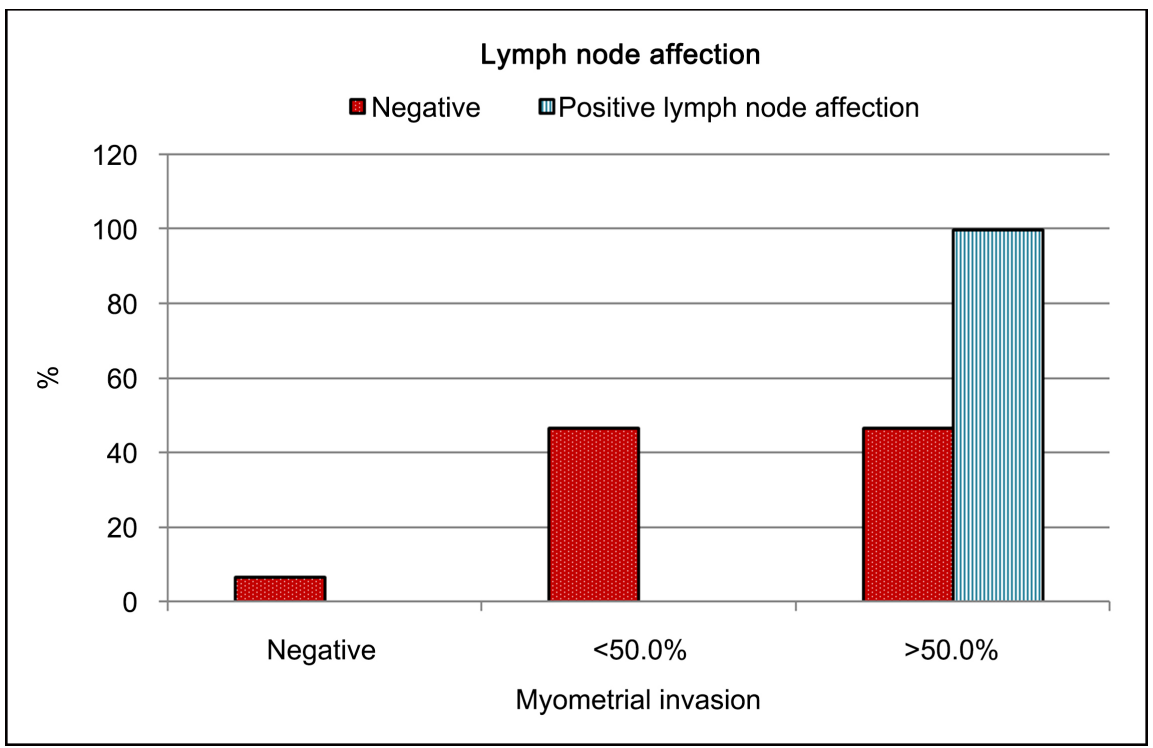

Figure 1. Relation between myometrial invasion and positive lymph node affection. 


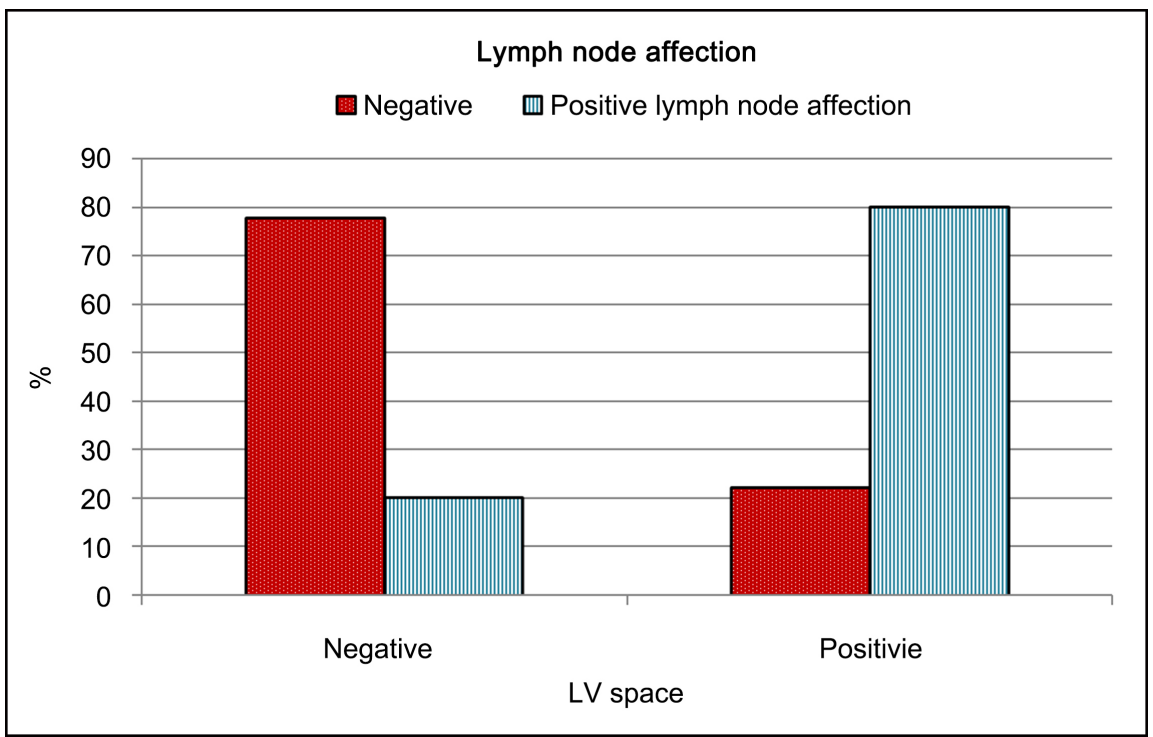

Figure 2. Relation between LV space and positive lymph node affection.

\section{Discussion}

Metastasis to pelvic lymph nodes is considered as a major prognostic factor in cases of endometrial cancer, the International Federation of Gynecology and Obstetrics (FIGO) recommended surgical staging must include sampling of regional lymph nodes and not the clinical staging alone [5]. By far, the lymph nodes are among the most common metastatic sites in endometrial carcinoma. The incidence of lymph node metastases in patients with FIGO grade 1 or 2 endometrial, endometrioid adenocarcinoma is low ranging from 5\% - 18\% [6] which was in accordance with our findings which was about $10 \%$ of cases (Table 1). The knowledge of lymph node status can provide important prognostic data to identify patients requiring adjuvant therapy. Lymph node metastasis can occur in patients with low grade endometrioid adenocarcinoma giving raise to advanced stage disease.

Few available data are available about the association of age and advanced stage disease. Older studies have pointed to increased age as a risk factor for poor outcome [7] [8], but these studies did not address the relationship of age to the presence of advanced stage disease (Table 1). A recent study assessing nodal metastasis risk utilizing triage criteria proposed by the Mayo Clinic [9] found that there is no significant age difference between patients with and without lymph node metastases. The present study showed that the median age was 64 years which represented $66 \%$ of cases as shown in Table 1 . Most of our endometrial sampling procedures were done using fractional curettage ( $98 \%$ of cases), while only $2 \%$ were taken using outpatient hystroscopy as shown in Table 2 .

Tumour grade in cases of type 1 (endometrioid) endometrial cancer is highly correlated with its stage and prognosis [10] being best in grade 1 and 2 and worst in grade 3 tumours (poorly differentiated type). One study showed no survival differences between grade 1 and grade 2 endometrial tumors [11]. A recent study 
by Euscher E et al. showed no difference in the risk of lymph node metastases or extrauterine disease between FIGO grade 1 and 2 tumors [12]. In this study, we found most of cases (48\%) were grade 2 endometrioid type (Table 2 and Table 3).

Transvaginal US in a major tool used in assessment of myometrial invasion in cases of EC. Irregularity of the junctional zone was seen in $72 \%$ of cases of EC (Table 1). The pathological results seen on microscopic assessment of MI showed that it was $52 \%$ of cases MI of more than half ( $>50 \%$ ) (Table 3 ). LVSI was positive in $72 \%$ of our cases.

Our study showed that there was a significant relation between the degree of myometrial invasion $(>50 \%)$ and pelvic lymph node affection. It was found that LN was positive in all cases where MI was more than $50 \%$ (Table 4). It was also found that pelvic LN affection was found in $80 \%$ of cases where LVSI was positive (Table 5).

Pelvic lymphadenectomy is a well-known surgical modality in cases of EC. It increases lymph node detection rate. One study reported that the number of pelvic lymph nodes sampled was a factor increasing the detection of lymph node metastases [13]. A later study demonstrated that the absolute lymph node count did not accurately predict the presence of lymph node metastases [6]. In our study, TAH with BSO and pelvic lymphadenectomy was performed in $52 \%$ of cases. The rate of pelvic $\mathrm{LN}$ affection is increased in cases where the myometrium was deeply invaded by thetumor (Table $6 \&$ Table 7, Figure $1 \&$ Figure 2).

Our study showed that there was a significant relation between the degree of myometrial invasion $(>50 \%)$ and pelvic lymph node affection. It was found that $\mathrm{LN}$ was positive in all cases where MI was more than $50 \%$ (Table 4). It was also found that pelvic LN affection was found in $80 \%$ of cases where LVSI was positive (Table 5).

So we can conclude that the incidence of pelvic lymph node affection is very high in cases where the myometrium is deeply infiltrated with the tumor. Assessment of myometrial invasion preoperatively by TVU and microscopically by pathological examination of the myometrium after hysterectomy provides an accurate estimation of the rate of pelvic lymph node affection and hence necessitates lymphadenectomy procedures in cases where myometrium is deeply infiltrated by the tumor and omitted in cases where it is tumor free.

\section{Conflicts of Interest}

The author declares no conflicts of interest regarding the publication of this paper.

\section{References}

[1] Siegel, R., Naishadham, D. and Jemal, A. (2012) Cancer Statistics, 2012. CA: $A$ Cancer Journal for Clinicians, 62, 10-29. https://doi.org/10.3322/caac.20138

[2] Pavlakis, K., Messini, I., Vrekoussis, T., et al. (2011) MELF Invasion in Endometrial Cancer as a Risk Factor for Lymph Node Metastasis. Histopathology, 58, 966-973. 
https://doi.org/10.1111/j.1365-2559.2011.03802.x

[3] Hirano, Y., Kubo, K., Hirai, Y., Okada, S., Yamada, K., Sawano, S., et al. (1992) Preliminary Experience with Gadolinium-Enhanced Dynamic MR Imaging for Uterine Neoplasms. Radio Graphics, 12, 243-256. https://doi.org/10.1148/radiographics.12.2.1561414

[4] Lien, H.H., Blomlie, V., Tropé, C., Kaern, J. and Abeler, V.M. (1991) Cancer of the Endometrium: Value of MR Imaging in Determining Depth of Invasion into the Myometrium. American Journal of Roentgenology, 157, 1221-1223.

https://doi.org/10.2214/ajr.157.6.1950869

[5] FIGO Committee (1989) Annual Report on the Results of Treatment in Gynecological Cancer. International Journal of Gynecology \& Obstetrics, 28, 189-193. https://doi.org/10.1016/0020-7292(89)90482-7

[6] Huang, M., Chadha, M., Musa, F., et al. (2010) Lymph Nodes: Is Total Number or Station Number a Better Predictor of Lymph Node Metastasis in Endometrial Cancer? Gynecologic Oncology, 119, 295-298.

[7] Lurain, J.R., Rice, B.L., Rademaker, A.W., et al. (1991) Prognostic Factors Associated with Recurrence in Clinical Stage I Adenocarcinoma of the Endometrium. Obstetrics \& Gynecology, 78, 63-69.

[8] Lee, K.R., Vacek, P.M. and Belinson, J.L. (1994) Traditional and Nontraditional Histopathologic Predictors of Recurrence in Uterine Endometrioid Adenocarcinoma. Gynecologic Oncology, 54, 10-18.

[9] Mariani, A., Dowdy, S.C., Cliby, W.A., et al. (2008) Prospective Assessment of Lymphatic Dissemination in Endometrial Cancer: A Paradigm Shift in Surgical Staging. Gynecologic Oncology, 109, 11-18. https://doi.org/10.1016/j.ygyno.2008.01.023

[10] Creasman, W.T., Morrow, P., Bundy, B.N., et al. (1987) Surgical Pathologic Spread Patterns of Endometrial Cancer. Cancer, 60, 2035-2041. https://doi.org/10.1002/1097-0142(19901015)60:8+<2035::AID-CNCR2820601515> $\underline{3.0 . \mathrm{CO} ; 2-8}$

[11] Scholten, A.N., Creutzberg, C.L., Noordijk, E.M., et al. (2002) Long-Term Outcome in Endometrial Carcinoma Favors a Two-Instead of a Three-Tiered Grading System. International Journal of Radiation Oncology, Biology, Physics, 52, 1067-1074. https://doi.org/10.1016/S0360-3016(01)02710-9

[12] Euscher, E., Fox, P., Bassett, R., et al. (2013) The Pattern of Myometrial Invasion as a Predictor of Lymph Node Metastasis or Extrauterine Disease in Low Grade Endometrial Carcinoma. The American Journal of Surgical Pathology, 37, 1728-1736. https://doi.org/10.1097/PAS.0b013e318299f2ab

[13] Kilgore, L.C., Partridge, E.E., Alvarez, R.D., et al. (1995) Adenocarcinoma of the Endometrium: Survival Comparisons of Patients with and without Pelvic Node Sampling. Gynecologic Oncology, 56, 29-33. 